KREATIF

Jurnal Ilmiah

Prodi Manajemen Universitas Pamulang
ISSN: 2339-0689 (Print), ISSN 2406-8616 (Online)

Volume 7, No 1 Juni 2019, (Halaman 103-114)

Tersedia online di http://openjournal.unpam.ac.id/index.php/kreatif

\title{
PENGARUH KEPEMIMPINAN KEPALA SEKOLAH DAN BUDAYA ORGANISASI TERHADAP KINERJA GURU (STUDY KASUS PADA YAYASAN PENDIDIKAN DARUSSALAM CIPUTAT, KOTA TANGERANG SELATAN)
}

\author{
Muhammad Gandung \\ Universitas Pamulang \\ dosen02020@unpam.ac.id
}

\begin{abstract}
ABSTRAK
Dengan melakukan penelitian ini maka akan di temukan bagaimana pengaruh kepemimpinan kepala sekolah dan budaya organiasi terhadap kinerja guru. Sebab itu perlu nya penelitian ini dengan melihat dari hipotesis seberapa pengaruh positifnya antara kepemimpinan dan budaya organisasi terhadap kinerja guru.

Metode penelitian menggunakan metode kuantitatif. Tempat penelitian di lakukan di YPI Darussalam dan waktu penelitian di jalankan 3 bulan. Metode di gunakan dengan wawancara, pengamatan dan kuesioner.

Dilihat dari koefisien determinasi sebesar 0,282 berarti menujukan ada pengaruh sebesar $28 \%$. Untuk $72 \%$ di karnakan faktor lain dan nilai F hitung (17.45) lebih besar dibandingkan dengan nilai $\mathrm{F}$ tabel $(2.71)$, dan sig, a $(0,000)$ lebih kecil dari pada alpha 5\% (0,005). Hal ini mengidentifikasikan bahwa hasil penelitian menolak Ho dan menerima Ha. Dengan demikian secara signifikan terhadap kinerja guru pada yayasan pendidikan islam Darussalam dan persamaan $31.370+0,137 \mathrm{X} 1+0,415 \mathrm{X} 2$ artinya ada persamaan tersebut dapat dilihat bahwa kepemimpinan dan budaya organisasi memiliki kemampuan untuk mempengaruhi kinerja guru pada yayasan pendidikan islam Darussalam.
\end{abstract}

Kata kunci : kepemimpinan, budaya organisasi, kinerja.

\section{ABSTRACT}

By conducting this research it will be found out how the influence of school principal leadership and organizational culture on teacher performance. Therefore this research needs to look at from the hypothesis how positive influence between leadership and organizational culture on teacher performance.

The research method uses quantitative methods. The research site was conducted at YPI Darussalam and the research time was carried out in 3 months. The method is used by interview, observation and questionnaire.

Judging from the coefficient of determination of 0.282 means there is an influence of $28 \%$. For $72 \%$ due to other factors and the calculated $F$ value (17.45) is greater than the F table value (2.71), and sig, a $(0,000)$ is smaller than the alpha $5 \%$ (0.005). This identified that the results of the research rejected Ho and accepted Ha. Thus significantly to the performance of teachers at the Darussalam Islamic Education Foundation and the equation $31,370+0,137 X 1+0,415 X 2$ means that there are similarities that can be seen that the leadership and organizational culture has the ability to influence the performance of teachers at the Darussalam Islamic Education Foundation. 
Keywords: leadership, organizational culture, performance.

\section{PENDAHULUAN}

\section{A. Latar Belakang Masalah}

Usaha pemerintan yang meningkatkan taraf pendidikan dengan melakukan dan membenahi kurikulum, buku pendidikan hingga sistem pendidikan yang merupakan suatu gejala untuk mensejahterahkan pendidikan saat ini sudah memberikan kemajuan yang sangat baik. Dilihat dari kegiatan pendidikan yang di lakukan di sekolah-sekolah sudah juga mendapatkan pujian yang baik, terutama kepemimpinan kepala sekolah yang menjadi teladan bagi guru dan murid untuk berperan serta dalam mensukseskan pendidikan ini.

Keadaan sekolah atau budaya organisasi sangat berpengaruh untuk proses mengajar para guru. Wibowo (2011) ada beberapa hal yang perlu di utamakan dalam meningkatkan hasil kinerja guru, yaitu nilai-nilai yang dapat di pahami, manajemen yang baik, tenaga pendidik, keadaan lingkungan, hubungan antar guru, saling menciptakan kegiatan gotong royong yang baik.

\section{B. Rumusan Masalah}

1. Bagaimana pengaruh kepemimpinan kepala sekolah terhadap kinerja guru?

2. Bagaimana pengaruh budaya organisasi terhadap kinerja guru?

3. Seberapa besar pengaruh kepemimpinan kepala sekolah dan budaya organisasi terhadap kinerja guru.

\section{TINJAUAN PUSTAKA}

\section{A. Pengertian Kepemimpinan}

Pemimpin di dalam organisasi dapat menggerakan apa saja yang dapat di lakukan, terutama kepada bawahan, pemimpin yang baik harus mampu memahami para bawahannya sehingga sikap pemimpin yang baik ini dapat di jadikan cantoh yang baik untukbawahannya serta tidak melakukan tindakan yang sewenangwenang dalam memanfaatkan bawahannya.

\section{B. Pengertian Budaya Organisasi}

Budaya Organisasi Menurut Eldridge dan Crombie (1974) dikutip dari Wirawan (2007:7) kumpul beragam hal yang di jadikan satu tujuan. Di samping itu perbedaan juga mencerminkan interaksi yang terdiri dari proses belajar, saling berbagi, bergotong royong, berpendapat baik, dan adaptasi yang merupakan karakteristik budaya sebagai ekspresi budaya melalui nilai-nlai kehidupan dan lingkungan sekitarnya.

\section{Pengertian Kinerja}

Sebagai bahasan tentang kinerja ini adalah merupakan inspirasi penulis untuk mengetahui lebih dalam arti pentingnya kinerja, maka penulis mencoba mendeskripsikan kinerja dari beberapa para ahli dengan teori-teorinya.

\section{Hipotesis}

Hipotesis nol (Ho) : $r=0$ : Tidak adanya perngaruh kepemimpinan kepala sekolah budaya organisasi terhadap kinerja guru.

Hipotesis (Ha) $: r \neq 0$ : Terdapat pengaruh kepemimpinan kepala sekolah dan budaya organisasi terhadap kinerja guru.

\section{METODOLOGI PENELITIAN}

\section{A. Tempat dan Waktu Penelitian}


Penelitian penelitian pada Yayasan Pendidikan Islam Darussalam, sebuah sekolah swasta yang ada di Kota Tangerang Selatan Provinsi Banten. Waktu penelitian di lakukan selama 3 bulan dilaksanakan mulai bulan Januari 2016 sampai dengan bulan April 2016.

\section{B. Populasi dan Sampel}

Banyaknya populasi yang akan dipilih adalah seluruh guru di YPI Darussalam berjumlah 121.

Dengan tingkat kesalahan 5\%, dengan rumus slovin yang dikutip oleh Husein Umar (2001), yaitu sebagai berikut :

$$
\begin{aligned}
& \mathrm{n}=\frac{121}{1+121(0,05)^{2}} \\
& \mathrm{n}=\frac{121}{1+121(0,0025)} \\
& \mathrm{n}=\frac{121}{1+0,3025} \\
& \mathrm{n}=\frac{121}{1,3025} \\
& \mathrm{n}=92
\end{aligned}
$$

Jadi jumlah sampel sebanyak 92, berarti sampel yang akan mewakili populasi adalah 92 guru.

\section{Teknik Pengumpulan Data}

1. Wawancara.

2. Kuesioner (Angket)

3. Observasi

\section{Metode Analisis Data}

\section{Uji Validitas}

Untuk membuktikan kuesioner benar, maka harus di uji validitas.

\section{Uji Reliabilitas}

$$
r_{X_{t} X_{t}}=\frac{\mathrm{n} \sum x_{i} x_{t}-\left(\sum x_{i}\right)\left(\sum \mathrm{x}_{\mathrm{t}}\right)}{\sqrt{\left\{\mathrm{n} \sum x_{\mathfrak{i}}^{2}-\left(\sum x_{\mathrm{i}}\right)^{2}\right\}\left\{\mathrm{n} \sum x_{\mathrm{t}}^{2}-\left(\sum x_{t}\right)^{2}\right\}}}
$$

Pengujian realibilitas dengan alpha cronbach.

\section{Uji Asumsi Klasik}

$$
r_{i}=\left[\frac{k}{(k-1)}\right]\left[1-\frac{\sum \mathrm{si}^{2}}{s t^{2}}\right]
$$
a. Uji Multikolinieritas
Menguji adakah dalam model regresi ditemukan nilai korelasi antar variabel bebas (independen).
b. Uji Heteroskedasitas
Menguji adakah dalam model regresi terjadi ketidaksamaan nilai dan residual satu pengamatan ke pengamatan yang lain.
c. Uji Normalitas sekitar nol (data normal)
Menguji adakah data yang di analisis memiliki nilai residual berada di

\section{Uji Hipotesis}
a. Uji Koefisien Determinasi
Mengetahui besar kontribusi variabel x1, x2 terhadap variabel y
b. Uji t: Mengetahui apakah $\mathrm{x} 1$, x2 memiliki pengaruh yang signifikan terhadap y.


c. Uji F: Menentukan apakah variabel independent berpengaruh secara simultan signbifikan terhadap variabel dependen

PEMBAHASAN

Tabel 1.1

Analisis Kuesioner Variabel Kepemimpinan

\begin{tabular}{|c|c|c|c|c|c|c|c|}
\hline \multirow{2}{*}{ No } & \multirow{2}{*}{ Indikator } & \multirow{2}{*}{ Pernyataan } & \multicolumn{5}{|c|}{ Skala } \\
\hline & & & SS & $\mathbf{S}$ & $\mathbf{R}$ & TS & STS \\
\hline 1 & Kemampuamengawasi & $\begin{array}{l}\text { 1. memberikan } \\
\text { pengarahan } \\
\text { kepada pada } \\
\text { saat } \\
\text { memberikan } \\
\text { tugas. } \\
\text { 2. Kepala sekolah } \\
\text { berkeliling } \\
\text { mengawasi } \\
\text { Guru dalam } \\
\text { berkerja. } \\
\text { 3. Kepala sekolah } \\
\text { membantu guru } \\
\text { mengawasi } \\
\text { murid }\end{array}$ & 62 & 30 & 0 & 0 & 0 \\
\hline 2 & $\begin{array}{l}\text { Kemampuan untuk } \\
\text { memotivasi }\end{array}$ & $\begin{array}{l}\text { 1. Kepala sekolah } \\
\text { mendukung } \\
\text { guru yang } \\
\text { berprestasi. } \\
\text { 2. Kepala sekolah } \\
\text { ciptakan } \\
\text { lingkungan } \\
\text { kerja yang baik. } \\
\text { 3. Kepala sekolah } \\
\text { member hadiah } \\
\text { pada guru yang } \\
\text { berprestasi }\end{array}$ & $\begin{array}{l}39 \\
68\end{array}$ & $\begin{array}{l}53 \\
24\end{array}$ & 2 & $\begin{array}{l}0 \\
0\end{array}$ & $\begin{array}{l}0 \\
0\end{array}$ \\
\hline 3 & $\begin{array}{l}\text { Ketegasan dalam } \\
\text { mengambil keputusan. }\end{array}$ & $\begin{array}{l}\text { 1. Kepala sekolah } \\
\text { bersikap adil } \\
\text { terhadap guru. } \\
\text { 2. Kepala sekolah } \\
\text { bijaksana } \\
\text { member } \\
\text { keputusan. } \\
\text { 3. Kepala sekolah } \\
\text { melibatkan guru } \\
\text { dalam } \\
\text { mengambil } \\
\text { keputusan }\end{array}$ & $\begin{array}{l}50 \\
49\end{array}$ & $\begin{array}{l}39 \\
37\end{array}$ & 2 & $\begin{array}{l}1 \\
3\end{array}$ & $\begin{array}{l}0 \\
1\end{array}$ \\
\hline 4 & $\begin{array}{l}\text { Kemampuan dalam } \\
\text { komunikasi }\end{array}$ & $\begin{array}{l}\text { 1. Kepala sekolah } \\
\text { meiliki selera } \\
\text { humor. }\end{array}$ & $\begin{array}{l}49 \\
65 \\
\end{array}$ & $\begin{array}{l}40 \\
25 \\
\end{array}$ & 2 & $\begin{array}{l}1 \\
2 \\
\end{array}$ & $\begin{array}{l}0 \\
0 \\
0\end{array}$ \\
\hline
\end{tabular}




\begin{tabular}{|c|c|c|c|c|c|c|c|}
\hline & & $\begin{array}{l}\text { 2. Kepala sekolah } \\
\text { menerima saran } \\
\text { dan masukan. } \\
\text { 3. Kepala sekolah } \\
\text { suka } \\
\text { berkomunikas } \\
\text { dgn guru }\end{array}$ & 38 & 50 & 0 & 4 & 0 \\
\hline 5 & Keteladanan & $\begin{array}{l}\text { 1. Kepala sekolah } \\
\text { datang tepat } \\
\text { waktu. } \\
\text { 2. Kepala sekolah } \\
\text { mengikuti } \\
\text { prosedur dengan } \\
\text { benar. } \\
\text { 3. Kepala sekolah } \\
\text { berpakaian } \\
\text { rapih }\end{array}$ & $\begin{array}{l}50 \\
51\end{array}$ & $\begin{array}{l}40 \\
40\end{array}$ & 0 & 2 & $\begin{array}{l}0 \\
0\end{array}$ \\
\hline
\end{tabular}

Dari hasil penyebaran 15 pernyataan tentang kepemimpinan kepala sekolah yang diberikan kepada seluruh responden berjumlah 92 orang, peneliti dapat menganalisa jawaban sebagai berikut :

$$
\begin{gathered}
\mathrm{SS}=\frac{776}{1380} \times 100 \%=56,23 \% \\
\mathrm{~S}=\frac{576}{1380} \times 100 \%=41,73 \% \\
\mathrm{R}=\frac{10}{1380} \times 100 \%=0,72 \% \\
\mathrm{TS}=\frac{16}{1380} \times 100 \%=1,15 \% \\
\mathrm{STS}=\frac{2}{1380} \times 100 \%=0,14 \%
\end{gathered}
$$

\begin{tabular}{|c|c|c|c|c|c|c|c|}
\hline \multirow{2}{*}{ No } & \multirow{2}{*}{ Indikator } & \multirow{2}{*}{ Pernyataan } & \multicolumn{5}{|c|}{ Skala } \\
\hline & & & SS & $\mathbf{S}$ & $\mathbf{R}$ & TS & STS \\
\hline 1 & Kerja Sama & $\begin{array}{l}\text { 1. kerjasama dalam } \\
\text { menciptakan } \\
\text { suasana harmonis. } \\
\text { 2. Pencapaian Target } \\
\text { dapat dilakukan } \\
\text { dengan kerjasama. } \\
\text { 3. kerjasama } \\
\text { mempererat tali } \\
\text { pertemanan }\end{array}$ & 61 & 62 & 0 & 0 & 0 \\
\hline 2 & Kesadaran & $\begin{array}{l}\text { 1. Dalam lingkungan } \\
\text { sekolah menjaga } \\
\text { kebersihan. } \\
\text { 2. Sekolah mempunyai } \\
\text { aturan wajib tampil } \\
\text { rapih }\end{array}$ & $\begin{array}{l}64 \\
62\end{array}$ & 27 & 0 & 0 & 0 \\
\hline
\end{tabular}

Tabel 1.2

Analisis Kuesioner Variabel Budaya Organisasi 


\begin{tabular}{|c|c|c|c|c|c|c|c|}
\hline & & $\begin{array}{l}\text { 3. Seluruh anggota } \\
\text { sekolah menaati } \\
\text { aturan sekolah }\end{array}$ & & & & & \\
\hline 3 & $\begin{array}{l}\text { Perilaku } \\
\text { Kerja }\end{array}$ & $\begin{array}{l}\text { 1. Sikap ramah di } \\
\text { masukan dalam } \\
\text { peraturan sekolah. } \\
\text { 2. Sekolah } \\
\text { menghimbau agar } \\
\text { setiap anggotanya } \\
\text { senyum ke sesama. } \\
\text { 3. Mengerjakan tugas } \\
\text { dengan tidak } \\
\text { menganggu yg lain }\end{array}$ & 44 & 44 & 2 & 2 & 0 \\
\hline 4 & $\begin{array}{l}\text { Toleransi } \\
\text { kerja }\end{array}$ & $\begin{array}{l}\text { 1. Kepala sekolah dan } \\
\text { guru di beri } \\
\text { kebebasan dalam } \\
\text { berkerja. } \\
\text { 2. Kepala sekolah dan } \\
\text { guru saling } \\
\text { member dukungan. } \\
\text { 3. Kepala sekolah } \\
\text { menerima masukan } \\
\text { dan saran }\end{array}$ & 59 & 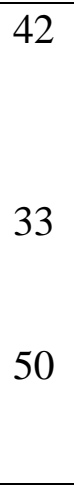 & 0 & 0 & 0 \\
\hline 5 & Kreativitas & $\begin{array}{l}\text { 1. Kepala sekolah dan } \\
\text { guru meberikan } \\
\text { inovasi. } \\
\text { 2. Kepala sekolah dan } \\
\text { guru memiliki ke- } \\
\text { unikan dalam } \\
\text { memotivasi. } \\
\text { 3. Kepala sekolah } \\
\text { mengajari guru baru }\end{array}$ & 48 & 26 & 0 & 0 & 0 \\
\hline
\end{tabular}

Dari hasil penyebaran 15 pernyataan tentang budaya organisasi yang diberikan kepada seluruh responden berjumlah 92 orang, peneliti dapat menganalisa jawaban sebagai berikut :

$$
\begin{gathered}
\mathrm{SS}=\frac{731}{1380} \times 100 \%=52,97 \% \\
\mathrm{~S}=\frac{631}{1380} \times 100 \%=45,72 \% \\
\mathrm{R}=\frac{9}{1380} \times 100 \%=0,65 \% \\
\mathrm{TS}=\frac{8}{1380} \times 100 \%=0,57 \% \\
\mathrm{STS}=\frac{1}{1380} \times 100 \%=0,07 \%
\end{gathered}
$$

\begin{tabular}{|c|c|c|c|c|c|c|c|}
\hline \multirow{2}{*}{ No } & \multirow{2}{*}{ Indikator } & \multirow{2}{*}{ Pernyataan } & \multicolumn{5}{|c|}{ Skala } \\
\hline & & & SS & $\mathbf{S}$ & $\mathbf{R}$ & TS & STS \\
\hline 1 & $\begin{array}{l}\text { Sikap dan } \\
\text { perilaku }\end{array}$ & $\begin{array}{l}\text { 1. Guru percaya diri } \\
\text { walaupun sedang }\end{array}$ & 56 & 34 & 0 & 0 & 0 \\
\hline
\end{tabular}

Tabel 1.3

Analisis Kuesioner Variabel Kinerja Guru 


\begin{tabular}{|c|c|c|c|c|c|c|c|}
\hline & & $\begin{array}{l}\text { menghadapi masalah } \\
\text { yang rumit. } \\
\text { 2. Guru bersikap jujur } \\
\text { dalam melaporkan } \\
\text { setiap hasil kerja. } \\
\text { 3. Guru tegas dan } \\
\text { disiplin }\end{array}$ & $\begin{array}{l}63 \\
44\end{array}$ & $\begin{array}{l}24 \\
48\end{array}$ & 0 & 0 & 0 \\
\hline 2 & $\begin{array}{l}\text { Tangung } \\
\text { Jawab }\end{array}$ & $\begin{array}{l}\text { 1. Guru menjaga } \\
\text { kepercayaan yang di } \\
\text { berikan pimpinan } \\
\text { 2. Guru menaati } \\
\text { peraturan yang sudah } \\
\text { dibuat. } \\
\text { 3. Guru malas } \\
\text { memeriksa pekerjaan } \\
\text { siswa karena terlalu } \\
\text { banyak }\end{array}$ & $\begin{array}{l}44 \\
49 \\
74\end{array}$ & $\begin{array}{l}48 \\
42 \\
15\end{array}$ & 3 & 0 & 0 \\
\hline 3 & $\begin{array}{l}\text { Disiplin } \\
\text { Kerja }\end{array}$ & $\begin{array}{l}\text { 1. Guru tepat waktu } \\
\text { dalam melaksanakan } \\
\text { pekerjaan. } \\
\text { 2. Guru mengikuti } \\
\text { prosedur yang sudah } \\
\text { dibuat oleh kepala } \\
\text { sekolah. } \\
\text { 3. Guru masuk kelas } \\
\text { tepat waktu }\end{array}$ & $\begin{array}{l}74 \\
47\end{array}$ & $\begin{array}{l}15 \\
42\end{array}$ & 3 & 0 & 0 \\
\hline 4 & Keterampilan & $\begin{array}{l}\text { 1. Guru } \\
\text { mengembangkan ide } \\
\text { baru untuk } \\
\text { meningkatkan } \\
\text { kinerja. } \\
\text { 2. Guru diberi } \\
\text { keleluasaan untuk } \\
\text { mengajar lebih dari } \\
\text { satu mata pelajaran } \\
\end{array}$ & 54 & 34 & 4 & 0 & 0 \\
\hline 5 & $\begin{array}{l}\text { Mampu } \\
\text { berkerja } \\
\text { sama }\end{array}$ & $\begin{array}{l}\text { 1. Guru menyelesaikan } \\
\text { tugas dari kepala } \\
\text { sekolah dengan } \\
\text { berkerja sama. } \\
\text { 2. Guru menyelesaiakan } \\
\text { tugas dengan tepat } \\
\text { waktu }\end{array}$ & 78 & 14 & 0 & 0 & 0 \\
\hline 6 & Motivasi & $\begin{array}{l}\text { 1. Guru menerima } \\
\text { bonus dari kepala } \\
\text { sekolah }\end{array}$ & 43 & 49 & 0 & 0 & 0 \\
\hline 7 & Inisiatif & $\begin{array}{l}\text { 1. Guru } \\
\text { mengembangkan } \\
\text { inisiatif agar berkerja } \\
\text { lebih efektif dan } \\
\text { efisien. }\end{array}$ & 51 & 41 & 0 & 0 & 0 \\
\hline
\end{tabular}


Dari hasil penyebaran 15 pernyataan tentang kinerja guru yang diberikan kepada seluruh responden berjumlah 92 orang, peneliti dapat menganalisa jawaban sebagai berikut :

$$
\begin{gathered}
\mathrm{SS}=\frac{524}{1380} \times 100 \%=95,79 \% \\
\mathrm{~S}=\frac{21}{1380} \times 100 \%=3,83 \% \\
\mathrm{R}=\frac{2}{1380} \times 100 \%=0,36 \% \\
\mathrm{TS}=\frac{0}{1380} \times 100 \%=0 \% \\
\mathrm{STS}=\frac{0}{1380} \times 100 \%=0 \%
\end{gathered}
$$

Tabel 1.4

Uji Validitas

\begin{tabular}{|c|c|c|c|c|c|c|}
\hline \multirow{2}{*}{$\begin{array}{c}\text { Kuesioner } \\
\text { Variabel }\end{array}$} & \multicolumn{2}{|c|}{ Valid } & \multicolumn{2}{c|}{ Tidak Valid } & \multicolumn{2}{c|}{ Total } \\
\cline { 2 - 7 } & Jml & $\%$ & Jml & $\%$ & Jml & $\%$ \\
\hline $\begin{array}{c}\text { Kepemimpinan } \\
\text { Kepala Sekolah } \\
\text { (X1) }\end{array}$ & 15 & $100 \%$ & 0 & $0 \%$ & 15 & $100 \%$ \\
\hline $\begin{array}{c}\text { Budaya } \\
\text { Organisasi (X2) }\end{array}$ & 15 & $100 \%$ & 0 & $0 \%$ & 15 & $100 \%$ \\
\hline $\begin{array}{c}\text { Kinerja Guru } \\
\text { (Y ) }\end{array}$ & 15 & $100 \%$ & 0 & $0 \%$ & 15 & $100 \%$ \\
\hline Jumlah & 45 & $100 \%$ & 0 & $0 \%$ & 45 & $100 \%$ \\
\hline
\end{tabular}

Berdasarkan data tabel $\mathrm{d}$ atas, ternyata seluruh item pernyataan merupakan item yang terplih dan dapat digunakan sebaga alat pengumpul data (kuesioner).

Tabel 1.5

\section{Uji Realibilitas}

\begin{tabular}{|c|c|c|}
\hline Variabel & Nilai Cronbach Alpha & Kriteria \\
\hline $\begin{array}{c}\text { Kepemimpinan Kepala } \\
\text { Sekolah (X1) }\end{array}$ & 0.754027 & Reliabilitas Tinggi \\
\hline Budaya Organisasi (X2) & 0.761554 & Reliabilitas Tinggi \\
\hline Kinerja Guru ( Y ) & 0.771308 & Reliabilitas Tinggi \\
\hline
\end{tabular}

Dari data di atas variabel kepemimpinan kepala sekolah (X1) adalah 0,754027 dengan kriteria reliabilitas tinggi, variabel budaya organisasi (X2) adalah 0,761554 dengan kriteria reliabilitas tinggi, variabel kinerja guru ( $\mathrm{Y}$ ) adalah 0,771308 dengan kriteria reliabilitas tinggi.

\section{Pengujian Hipotesis}

Uji yang dipakai seperti Uji Koefisdien Determinasi, Uji F dan Uji t :

\begin{tabular}{|c|c|c|c|c|c|c|}
\hline \multirow{2}{*}{\multicolumn{2}{|c|}{ Model }} & \multicolumn{2}{|c|}{$\begin{array}{c}\text { Unstandardized } \\
\text { Coefficients }\end{array}$} & \multirow{2}{*}{$\begin{array}{c}\text { Standardized } \\
\text { Coefficients } \\
\text { Beta }\end{array}$} & \multirow[b]{2}{*}{$\mathrm{t}$} & \multirow[b]{2}{*}{ Sig. } \\
\hline & & $\mathrm{B}$ & Std. Error & & & \\
\hline & (Constant) & 43.413 & 5.746 & & 7.555 & .000 \\
\hline & $\begin{array}{l}\text { Kepemimpina } \\
\mathrm{n}\end{array}$ & .373 & .084 & .422 & 4.416 & .000 \\
\hline
\end{tabular}

\section{Pengaruh $\mathrm{X} 1$ terhadap $Y$ dengan $\mathrm{Uji} t$}

\section{Tabel 1.6}

Tabel uji signifikan regresi X1 terhadap Y

Coefficients $^{\mathrm{a}}$

a. Dependent Variable: Kinerja 
sumber :Data Primer yang telah di olah.

Tabel 1.7

Koefisien Determinasi

X1 terhadap Y

Model Summary

\begin{tabular}{|l|c|r|r|r|}
\hline Model & R & R Square & $\begin{array}{c}\text { Adjusted R } \\
\text { Square }\end{array}$ & $\begin{array}{c}\text { Std. Error of } \\
\text { the Estimate }\end{array}$ \\
\hline 1 & $.422^{\mathrm{a}}$ & .178 & \multicolumn{1}{|c|}{.169} & 3.49520 \\
\hline
\end{tabular}

a. Predictors: (Constant), Kepemimpinan

b. Dependen variabel Kinerja

Sumber: Data primer yang telah di olah

Pengaruh Budaya Organisasi (X2) terhadap Kinerja Guru (Y) dengan Uji

Parsial (Uji t)

Tabel 1.8

Tabel Uji Signifikan Regresi X2 Terhadap Y

Coefficients $^{\text {a }}$

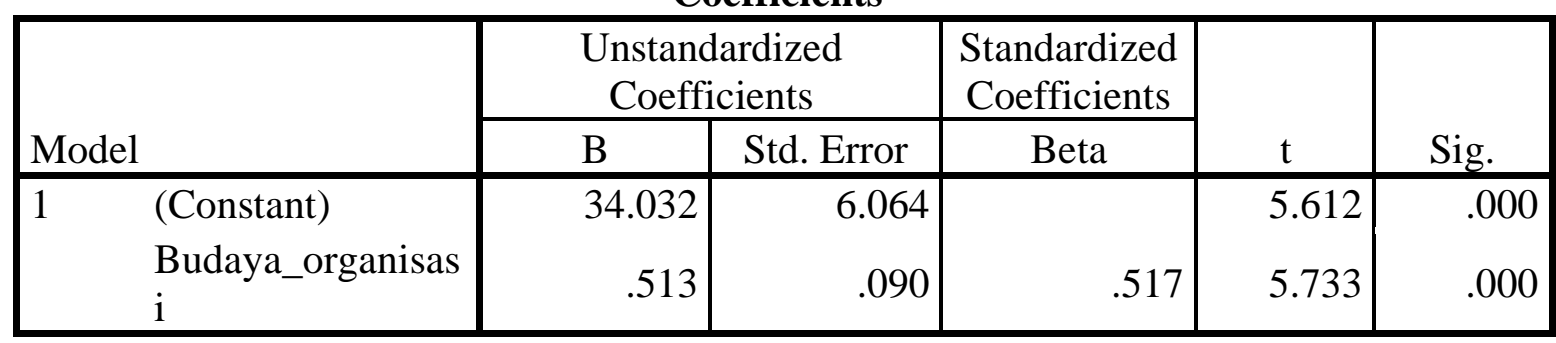

a. Dependent Variable: Kinerja

Sumber :Data Primer yang telah di olah

Tabel 1.9

Koefisien determinasi

Pengaruh X2 Terhadap Y

Model Summary

\begin{tabular}{|l|c|r|r|r|}
\hline Model & R & R Square & $\begin{array}{c}\text { Adjusted R } \\
\text { Square }\end{array}$ & $\begin{array}{c}\text { Std. Error of } \\
\text { the Estimate }\end{array}$ \\
\hline 1 & $.517^{\mathrm{a}}$ & .267 & .259 & 3.29967 \\
\hline
\end{tabular}

a. Predictors: (Constant), Budaya_organisasi

b. Dependen variabel: kinerja sumber: data primer yang telah diolah

2. Pengaruh Kepemimpinan (X1) Dan Budaya Organisasi (X2) Terhadap Kinerja Guru Dengan Uji Simultan (Uji F)

$$
\begin{aligned}
\mathrm{dk} & =\mathrm{n}-\mathrm{k}-1 \\
& =92-2-1 \\
& =89 \\
\mathrm{~F}_{\text {tabel }} & =\mathrm{F}(\mathrm{s} ; \mathrm{dk}) \\
& =(0,05 ; 89) \\
& =2,71
\end{aligned}
$$


Maka hipotesis ke empat akan menjadi :

H0 : Tidak ada pengaruh kepemimpinan dan budaya organisasi terhadap kinerja guru.

$\mathrm{Ha}$ : $\quad$ Ada pengaruh kepemimpinan dan budaya organisasi terhadap kinerja guru.

Tabel 1.20

Tabel Uji Signifikan Regresi Kepemimpinan Dan Budaya Organisasi Terhadap Kinerja Guru.

ANOVA ${ }^{a}$

\begin{tabular}{|c|c|c|c|c|c|c|}
\hline & & $\begin{array}{l}\text { Sum of } \\
\text { Squares }\end{array}$ & df & $\begin{array}{l}\text { Mean } \\
\text { Square }\end{array}$ & $\mathrm{F}$ & Sig. \\
\hline \multirow[t]{3}{*}{1} & Regression & 376.890 & 2 & \multirow{3}{*}{$\begin{array}{r}188.445 \\
10.796\end{array}$} & \multirow[t]{3}{*}{17.455} & \multirow[t]{3}{*}{$.000^{\mathrm{b}}$} \\
\hline & Residual & 960.849 & 89 & & & \\
\hline & Total & 1337.739 & 91 & & & \\
\hline
\end{tabular}

a. Dependent Variable: Kinerja

b. Predictors: (Constant), Budaya_Organisasi, Kepemimpinan

Sumber : hasil pengolahan SPSS

Tabel 1.21

Koefisien Determinasi Sacara Simultan

Model Summary ${ }^{b}$

\begin{tabular}{|l|c|r|r|r|}
\hline Model & R & R Square & $\begin{array}{c}\text { Adjusted R } \\
\text { Square }\end{array}$ & $\begin{array}{c}\text { Std. Error of } \\
\text { the Estimate }\end{array}$ \\
\hline 1 & $.531^{\mathrm{a}}$ & .282 & .266 & 3.28574 \\
\hline
\end{tabular}

a. Predictors: (Constant), Budaya_Organisasi,

Kepemimpinan

b. Dependent Variable: Kinerja

Sumber: Hasil penelitian, 2016 (Data Diolah)

Tabel 1.22

Hasil Regresi Berganda Kepemimpinan dan Budaya Organisasi Terhadap

Kinerja Guru.

Coefficients $^{\text {a }}$

\begin{tabular}{|c|c|c|c|c|c|c|}
\hline \multirow{2}{*}{\multicolumn{2}{|c|}{ Model }} & \multicolumn{2}{|c|}{$\begin{array}{l}\text { Unstandardized } \\
\text { Coefficients }\end{array}$} & \multirow{2}{*}{$\begin{array}{c}\text { Standardized } \\
\text { Coefficients }\end{array}$} & \multirow[b]{2}{*}{$\mathrm{t}$} & \multirow[b]{2}{*}{ Sig. } \\
\hline & & $\mathrm{B}$ & Std. Error & & & \\
\hline \multirow[t]{3}{*}{1} & (Constant) & 31.370 & 6.362 & & 4.931 & .000 \\
\hline & Kepemimpinan & .137 & .103 & .155 & 1.329 & .187 \\
\hline & $\begin{array}{l}\text { Budaya_Organisas } \\
\text { i }\end{array}$ & .415 & .116 & .418 & 3.583 & .001 \\
\hline
\end{tabular}

a. Dependent Variable: Kinerja

Sumber : Hasil Pengolahan SPSS 


\section{Pembahasan :}

\section{Pengaruh Kepemimpinan Kepala Sekolah Terhadap Kinerja Guru} signifikan.

Maka di peroleh $t_{\text {hitung }}(4.416)>(1.66196)$. berarti berpengaruh

\section{Pengaruh Budaya Organisasi Terhadap Kinerja Guru} signifikan.

Maka di peroleh thitung $(5.733)>(1.66196)$. berarti berpengaruh

3. Pengaruh Kepemimpinan dan Budaya Organisasi Terhadap Kinerja Guru

Dengan menggunakan tingkat signifikan 0,05 maka nilai tabel dengan $\mathrm{dk}=\mathrm{n}-\mathrm{k}-1=92-2-1=89$ di peroleh $\mathrm{F}_{\text {tabel }}$ sebesar 2,71 tingkat signifikan 0,000 . berarti berpengaruh signifikan.

\section{KESIMPULAN}

1. Hasil penelitian kepemimpinan terhadap kinerja dengan statistik menunjukan hasil signifikan. Dengan hipotesis menyatakan di peroleh $t_{h i t u n g}(4.416)>$ (1.66196). berarti berpengaruh signifikan.

2. Hasil penelitian budaya organisasi terhadap kinerja degan statistik menunjukan hasil signifikan. Dengan hipotesis menyatakan di peroleh $t_{\text {hitung }}(5.733)>$ (1.66196). berarti berpengaruh signifikan.

3. Hasil penelitian pengaruh kepemimpinan dan budaya organisasi secara bersama-sama terhadap kinerja guru secara statistik menunjukan hasil yang signifikan. Dengan demikian hipotesis menyatakan dengan menggunakan tingkat signifikan 0,05 maka nilai tabel dengan $\mathrm{dk}=\mathrm{n}-\mathrm{k}-1=92-2-1=89 \mathrm{di}$ peroleh $F_{\text {tabel }}$ sebesar 2,71 tingkat signifikan 0,000. berarti berpengaruh signifikan

\section{SARAN}

1. Berdasarkan peninjauan penulis instrument variabel kepemimpinan kepala sekolah pada Kemampuan dalam komunikasi perlu ada peningkatan komunikasi antara kepala sekolah dengan guru.

2. Berdasarkan peninjauan penulis instrument variabel budaya organisasi pada Kemampuan dalam komunikasi perlu ada peningkatan komunikasi antara kepala sekolah dengan guru.

\section{DAFTAR PUSTAKA}

Daito, Apollo. (2007). Metodologi Penelitian Penyusunan Skripsi/Tesis/Desertasi. Jakarta: Penerbit Fakultas Ekonomi Universitas Budi Luhur.

Ernie Tisnawati Sule. (2010). Pengantar Manajemen. Jakarta: Prenada Media Group. Edy Sutrisno. (2009). Manajemen Sumber Daya Manusia. Jakarta: Prenada Media Group.

E. Mulyasa. (2004). Menjadi Kepala SekolahProfesional. Bandung: Remaja Rosdakarta.

Fred Luthan. (2006). Organization Behavior. Yogyakarta: Edisi 10, Terjemahan, ANDI Copyright.

Khaerul Umam. (2010). Perilaku Organisasi.Bandung: Pustaka Setia.

Malayu Hasibuan S.P. (2005). Manajemen Sumber Daya Manusia, Jakarta: Edisi Revisi, Cetakan Ketujuh, Penerbit PT Bumi Aksara.

Mulyono, "Manajemen Administrasi dan Organisasi Pendidikan", Ar-Ruzz Media, 2009 
Notoatmojo Soekijo, "Pengembangan Sumber Daya Manusia“, Bhineka Cipta, Jakarta, 1998

Nanang Fattah, "Landasan Manajemen Pendidikan”, Remaja Rosdakarya, Bandung, 2004

Robbin S, "Perilaku Keorganisasian”, Edisi 5, Penerbit Erlangga, Jakarta, 2002

Riduwan. (2010). Metode dan Teknik-Teknik Menyusun Tesis. Bandung: cetakan ke tujuh, Penerbit ALFABETA.

Rivai V \& Sugula J E. (2010). Mmanajemen sumber daya manusia untuk perusahaan Jakarat: edisi kedua, cetakan ketiga, penerbit PT Raja Grafindo.

Samsudin, Sadili. (2006) Manajemen Sumber Daya Manusia. Bandung: Cetakan Pertama.Penerbit Pustaka Setia.

Syarifuddin Nurdin. (2005). Guru profesional \& Implementasi Kurikulum. „Jakarta Quantum Teaching. 